\title{
Carbon dioxide pneumothorax following retroperitoneal laparoscopic partial nephrectomy: a case report and literature review
}

Qiongfang $\mathrm{Wu}^{*}$ and Hong Zhang(D

\begin{abstract}
Background: Laparoscopy has many advantages when used to assist surgery. However, pneumothorax, as a rare but potentially life-threatening complication, it requires rapid recognition and treatment. $\mathrm{CO}_{2}$ pneumothorax may be distinct from air pneumothorax. Here we present a case with unexpected large and symptomatic $\mathrm{CO}_{2}$ pneumothorax and treated successfully in a conservative way.

Case presentation: A 27-year-old woman who was scheduled a laparoscopic partial nephrectomy received general anesthesia. At the end of surgery, she waked up and got spontaneous breathing. However, she developed a sudden fall in $\mathrm{SpO}_{2}$ (approximately 30\%) and blood pressure with subsequent unconsciousness after switching mechanical ventilation to spontaneous mode. With immediate manual ventilation, $\mathrm{SpO}_{2}$ and blood pressure recovered simultaneously and the patient regained consciousness. Point-of-care chest $X$-ray revealed a large, right pneumothorax occupying $70 \%$ of the hemi-thorax. Without chest drainage, she was extubated in the operating room and treated with supplemental facial mask oxygen therapy in PACU. On the postoperative 5th day, she was discharged without any further complication.

Conclusion: Retroperitoneal laparoscopic surgeries are likely to bring about severe capno-thorax, which could be absorbed rapidly. Chest X-ray could be used to assist diagnosis but point-of-care transthoracic ultrasound is recommended. Even severe capno-thorax could be treated conservatively. This case highlights the awareness and therapeutic choice of noninvasive management for capno-thorax.
\end{abstract}

Keywords: Carbon dioxide, Pneumothorax, Laparoscopy, Case report

\section{Background}

Laparoscopic surgeries have been widely performed because they have so many advantages as less invasiveness, less postoperative pain, shorter hospital stay and better cosmesis [1]. However, they may also cause severe complications like pneumothorax, pneumomediastinum and subcutaneous emphysema [2]. Laparoscopic partial nephrectomy, which could be performed through insufflating carbon dioxide $\left(\mathrm{CO}_{2}\right)$ in either the retroperitoneal or peritoneal space to achieve a better view, has been widely used for surgical treatment for $\mathrm{T} 1$ stage renal

\footnotetext{
* Correspondence: zhanghong40@hotmail.com

Departments of Anesthesiology and Critical Care Medicine, Peking University First Hospital, Beijing 100034, China

tumor. Pneumothorax is a recognized complication of laparoscopic surgery $[3,4]$. Although the incidence of pneumothorax in laparoscopic renal surgery is less than $1 \%$, it's potentially serious and life-threatening [5], requiring rapid recognition and treatment. For patients with large pneumothorax or obvious symptoms, the common practice is to place a chest tube for drainage. However, $\mathrm{CO}_{2}$ pneumothorax is distinct from air pneumothorax in that $\mathrm{CO}_{2}$ is highly soluble in blood and could be absorbed rapidly [6,7]. Here, we present a case with an unexpected large volume of $\mathrm{CO}_{2}$ pneumothorax and severe symptoms, which was managed conservatively.

(c) The Author(s). 2018 Open Access This article is distributed under the terms of the Creative Commons Attribution 4.0 International License (http://creativecommons.org/licenses/by/4.0/), which permits unrestricted use, distribution, and reproduction in any medium, provided you give appropriate credit to the original author(s) and the source, provide a link to the Creative Commons license, and indicate if changes were made. The Creative Commons Public Domain Dedication waiver (http://creativecommons.org/publicdomain/zero/1.0/) applies to the data made available in this article, unless otherwise stated. 


\section{Case presentation}

A 27-year-old woman (height $165 \mathrm{~cm}$; weight $92 \mathrm{~kg}$ ) was admitted to hospital for management of a $1.8 \mathrm{~cm} \times 1.3$ $\mathrm{cm} \times 1.7 \mathrm{~cm}$ renal mass in the lower pole of the right kidney (examined by MRI) and scheduled for laparoscopic partial nephrectomy under general anesthesia. The patient mentioned she had no other medical history but congenital asymptomatic platybasia. The laboratory examinations were normal except uric acid $425 \mu \mathrm{mol} / \mathrm{L}$ (the normal range is $90-360 \mu \mathrm{mol} / \mathrm{L}$ ). There was no abnormity for electrocardiogram (ECG) or chest X-ray.

On the operating day, the patient entered the operating room without premedication. ECG, $\mathrm{SpO}_{2}$, end-tidal carbon dioxide pressure $\left(\mathrm{PetCO}_{2}\right)$ and bispectral index (BIS) were monitored. A $20 \mathrm{G}$ catheter was inserted into her left radial artery to ensure real-time blood pressure monitoring. Anesthesia was induced with remifentanil (target-controlled infusion at effect-site concentration of $3 \mathrm{ng} / \mathrm{mL}$ ), $150 \mathrm{mg}$ propofol and $50 \mathrm{mg}$ rocuronium. A 7 $\mathrm{mm}$ ID endotracheal tube was intubated with an insertion distance of $21 \mathrm{~cm}$ at the incisors. The patient was ventilated with volume controlled ventilation mode (setting tidal volume at $500 \mathrm{ml}$, respiratory rate at 12 times/ min, inspiration and expiration ratio at 1:2) and was placed in the left lateral decubitus position. Before pneumoperitoneum, airway pressure was controlled within 20 $\mathrm{cmH}_{2} \mathrm{O}$ and $\mathrm{PetCO}_{2}$ was controlled between 31 and 35 $\mathrm{mmHg}$. Anesthesia was maintained with intravenous remifentanil (target-controlled infusion at effect-site level of $2-3 \mathrm{ng} / \mathrm{mL}$ ), propofol (constant infusion), and $60 \%$ nitrous oxide balanced with oxygen. Sufentanil (totally $20 \mu \mathrm{g}$ ) and cisatracurium (totally $2 \mathrm{mg}$ ) was intermittently injected intravenously and the infusion speed of propofol was adjusted according to BIS within the range of 40 to 60 .

The procedure was uneventful though there was an episode. After finishing the first trocar portal, a balloon, made from a sutured latex glove, was used to inflate and dilate retroperitoneum cavity. But the balloon was ruptured during inflation and the suture on the balloon was left in retroperitoneum space. Finally, the suture was found and removed after a period of searching with the help of laparoscopy. Procedure was performed via 3 successfully established trocar portals. The retroperitoneal space was hydrostatically dilated and $\mathrm{CO}_{2}$ was insufflated to a pressure of $14 \mathrm{mmHg}$. During the procedure, the airway pressure increased to $30 \mathrm{cmH}_{2} \mathrm{O}$ and $\mathrm{PetCO}_{2}$ was elevated to $41 \mathrm{mmHg}$. $\mathrm{SpO}_{2}$ remained $100 \%$. We adjusted tidal volume to $550 \mathrm{ml}$ and respiratory rate to 13 times/min. At the end of the surgery, the retroperitoneal carbon dioxide was retreated and airway pressure decreased to $23-24 \mathrm{cmH}_{2} \mathrm{O}$. Operative duration was almost 90 min, during which the hemodynamic parameters were stable. We stopped all intravenous anesthetics and changed the gas supply to $100 \% \mathrm{O}_{2}$ with a flow rate of 5 $\mathrm{L} / \mathrm{min}$. The patient woke up quickly and could respond to instructions. Then the patient was placed to supine position. Mechanical ventilation was ceased and the patient had spontaneous breathing. Antagonists of muscle relaxant (neostigmine $2 \mathrm{mg}$ plus atropine $1 \mathrm{mg}$ ) were given. Two minutes after the stop of mechanical ventilation, $\mathrm{SpO}_{2}$ decreased rapidly to $30 \%$ and blood pressure decreased from $120 / 79 \mathrm{mmHg}$ to $93 / 65 \mathrm{mmHg}$. The patient was unconscious. We conducted manual ventilation immediately and then $\mathrm{SpO}_{2}$ returned to $85-90 \%$. Meanwhile, blood pressure recovered. Immediate auscultation showed decreased breath sounds on the right side of chest and the left side was normal. Immediate arterial blood gas analysis showed $\mathrm{PCO}_{2} 75 \mathrm{mmHg}, \mathrm{PO}_{2} 83 \mathrm{mmHg}$. We woke up the patient and she could breathe spontaneously with better tidal volume. We extubated her endotracheal tube and provided oxygen via facemask. She was able to breathe without distress but felt right chest pain. $\mathrm{SpO}_{2}$ climbed to $91-93 \%$ gradually. Point-of-care chest X-ray was performed, demonstrating a large, right pneumothorax occupying $70 \%$ of the hemithorax (Fig. 1).

The patient was transferred to post-anesthesia care unit and stayed for $1 \mathrm{~h}$ with facemask oxygen inhalation (oxygen flow rate $5 \mathrm{~L} / \mathrm{min}$ ). Her vital signs were normal during the period and $\mathrm{SpO}_{2}$ returned to $100 \%$. She felt right chest pain relieved a bit. Arterial blood gas was re-examined and all parameters were in normal range. The patient was later sent back to general ward.

In general ward, respiratory and hemodynamic parameters of the patient remained stable during hospital stay. Chest X-ray taken on the first post-operative day revealed complete re-expansion of the right lung (Fig. 2). She claimed no chest pain and no other symptoms. The patient was discharged home on postoperative day 5 .

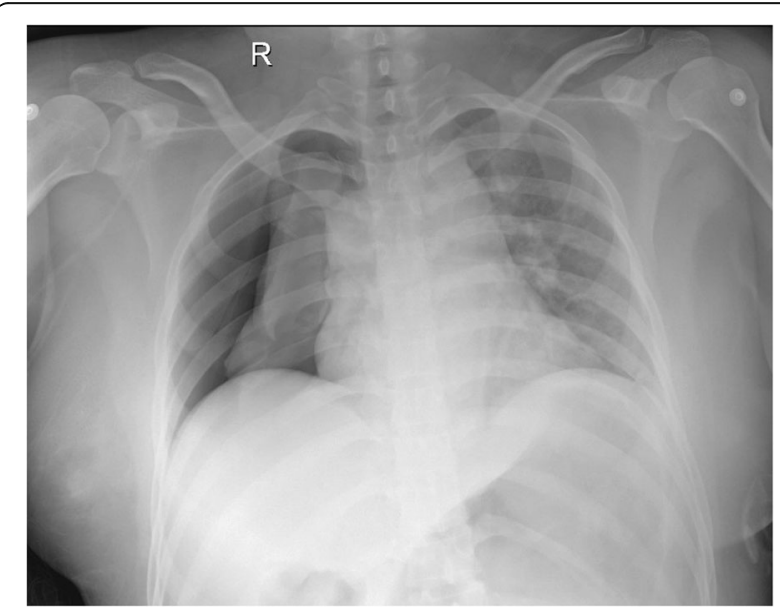

Fig. 1 Chest $X$-ray in the operating room 


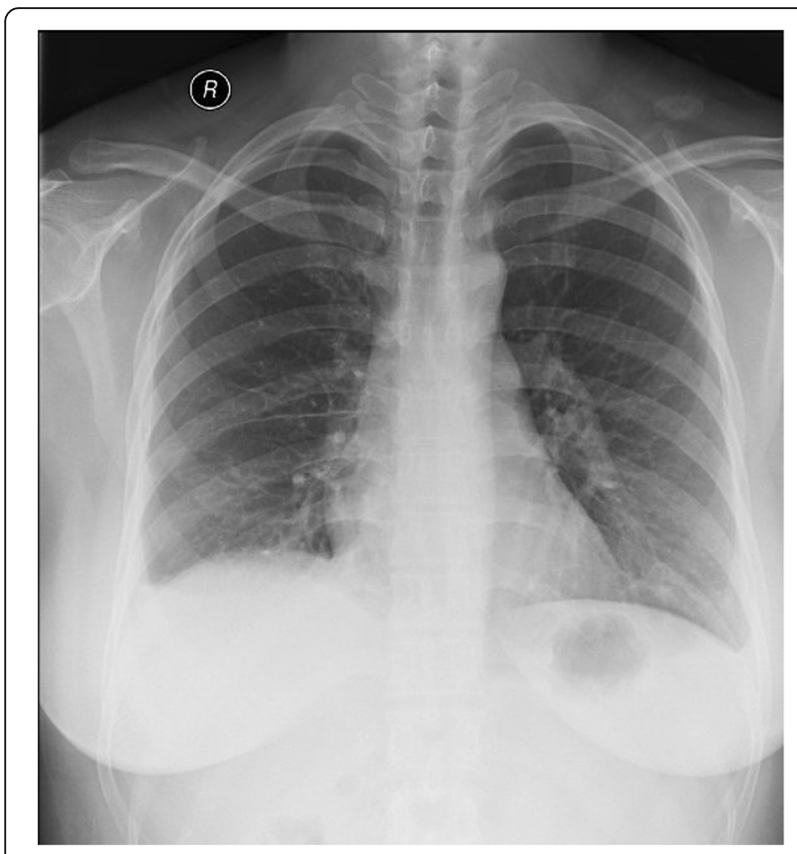

Fig. 2 Chest $X$-ray on the first postoperative day

\section{Discussion and conclusion}

Large or symptomatic pneumothorax usually necessitates thoracocentesis or chest tube placement. But capno-thorax may warrant a different treatment. Table 1 summarized cases which reported moderate to large symptomatic capno-thorax while implemented conservative treatments. Different from these described above, in our case, the type of surgery route was retroperitoneal. The symptom was more severe $\left(\mathrm{SpO}_{2} 30 \%\right)$ and happened after gas deflation and before extubation. The patient was awake at first but fell into unconsciousness later. It's more urgent and hard for us to diagnose and decide whether it was suitable to adopt an invasive method. Fortunately, the severe condition didn't last for a long time. We also retrieved some cases in whom capno-thorax occurred in retroperitoneal urological surgeries. But most of these happened intraoperatively and implemented thoracocentesis or chest tube placement [8-11], or had confirmed diaphragm injury and recovered after converting to open surgery [12]. Although study showed $\mathrm{CO}_{2}$ absorption during laparoscopy did not depend on the route of surgery $[13,14]$, for retroperitoneal route, the restriction on working space and field of view may increase the risk of inadvertent organ damage.

\section{Causes for pneumothorax}

Pneumothorax during laparoscopic procedures has been reported and the possible causes are [3, 8-14]: First, barotrauma and rupture of bullae during mechanical ventilation or during central venous line placement may contribute to air pneumothorax. Second, unrecognized congenital defect such as diaphragmatic defects [15] or pleuroperitoneal fistulas could predispose patients to pneumothorax. Third, increased operative duration is likely to compel more $\mathrm{CO}_{2}$ absorption. Study showed that $\mathrm{PetCO}_{2}$ greater than $50 \mathrm{mmHg}$ and operative time greater than 200 min were risk factors for pneumothorax [16]. Fourth, higher insufflation pressure likely leads to a large amount of $\mathrm{CO}_{2}$ absorption. Several cases have been reported to get pneumothorax during laparoscopic surgeries with an insufflation pressure of $12-15 \mathrm{mmHg}$ [2, $17,18]$ whereas insufflation pressure under $12 \mathrm{mmHg}$ might still cause pneumothorax [19]; furthermore, rapid insufflation would allow the intracavitary pressure to increase suddenly, contributing to pneumothorax [11] because retroperitoneal space is not a true cavity and has lower compliance than the abdominal cavity. Fifth, it is also possible for $\mathrm{CO}_{2}$ to dissect into the pleural space along the vena cava or aorta [16]. Finally, pleural injury due to errant trocar placement or diaphragmatic injury possibly accounts for pneumothorax $[4,20]$.

In our case, the symptomatic pneumothorax was unanticipated as the procedure and anesthesia practice was uneventful. The patient was young and healthy. Operating duration and intraoperative $\mathrm{PetCO}_{2}$ were also acceptable. But the diaphragmatic defect cannot be excluded. Though operation on the lower pole of the kidney is less likely to injure diaphragm, the procedure to explore the lost suture might injure it unconsciously. Besides, $\mathrm{CO}_{2}$ could also dissect into the pleural space along the vena cava. All these possible reasons suggest not air but $\mathrm{CO}_{2}$ pneumothorax.

\section{Clinical manifestations and diagnosis}

Pneumothorax could bring out pulmonary atelectasis, elevate inspiratory airway pressure, $\mathrm{PetCO}_{2}$ as well as $\mathrm{PaCO}_{2}$ and decrease breath sounds and blood pressure. Hypotension occurs due to the decreased venous return and cardiac output. However, in this case, these changes were not obvious during procedure but appeared after the termination of mechanical ventilation. Possible reasons are that respiratory depression after the cessation of mechanical ventilation combined with pneumothorax exaggerated the clinical manifestation.

Chest computer tomography scan is the gold standard for diagnosis of pneumothorax [21, 22]. Chest X-ray is usually as the initial tool to detect the potential cases. All the cases list above was diagnosed by Chest X-ray. However, it has been demonstrated that point-of-care transthoracic ultrasound, a cheaper, nonradiative and timely tool, is more accurate than chest X-ray with $81 \%$ sensitivity and $100 \%$ specificity [23, 24]. Anterior absent lung sliding plus A lines plus lung point indicated pneumothorax [23]. If lung is totally collapsed, lung point isn't visualized; lung point on the mid axillary line 


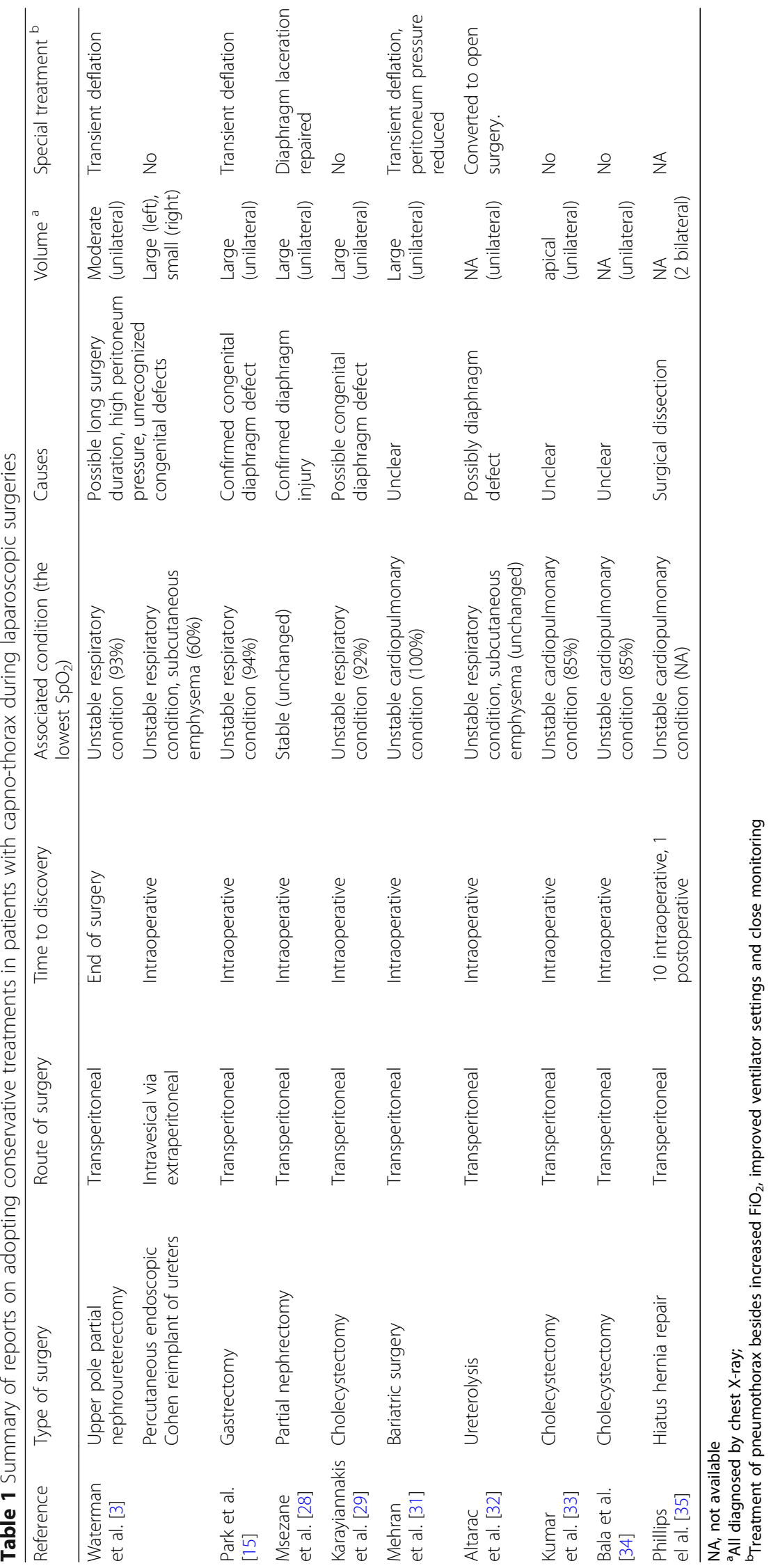


differentiates large and small pneumothorax, coinciding with a cut-off set at $15 \%$ of lung collapse [25], and could guide decision-making in treatments. This technique is extremely important for anesthesiologists to practice in the operating room. However, we didn't perform ultrasound scan because of inexperience.

\section{Practice taken to alleviate carbon dioxide pneumothorax}

The treatment can vary depending on the causes and severity of the pneumothorax. $\mathrm{FiO}_{2}$ should be increased and $\mathrm{N}_{2} \mathrm{O}$ supply should be stopped. $\mathrm{CO}_{2}$ insufflation could be reduced or discontinued. Endotracheal intubation, hyperventilation and higher positive end-expiratory pressure should be maintained [26].

Traditionally, a chest tube could be placed if a large pneumothorax or consequent cardiovascular or respiratory collapse is diagnosed. But capno-thorax may warrant a different treatment strategy. The solubility of $\mathrm{CO}_{2}$ is 20 times more than nitrogen and has an increased diffusion coefficient compared to air, which is composed mostly of nitrogen and oxygen. Higher solubility of a gas means more molecules can diffuse across a membrane in a given time. Experimental and clinical evidence demonstrated that resolution of capno-thorax can be more rapid than air pneumothorax, and usually complete re-expansion of the compressed lung could be achieved within several hours [15, 27-29], even within 30-60 min [30].We didn't implement thoracentesis or place a chest tube but provided oxygen supply and intensive care because it is found that the probability of pneumothorax caused by $\mathrm{CO}_{2}$ is higher than that by air, patient's condition was getting better and the source of $\mathrm{CO}_{2}$ was no longer feeding the retroperitoneum. The woman returned to normal state within $1 \mathrm{~h}$ although chest pain disappeared completely the next day.

In conclusion, pneumothorax, although rare, is a serious complication of laparoscopic nephrectomy. Anesthesiologists, when facing this crisis, should recognize pneumothorax right away. Point-of-care transthoracic ultrasound should be recommended to diagnose. Different from air pneumothorax, $\mathrm{CO}_{2}$ pneumothorax, even with a large volume, can be resolved spontaneously without invasive management.

\section{Abbreviations}

BIS: bispectral index; $\mathrm{CO}_{2}$ : carbon dioxide; CXR: chest X-ray; ECG: electrocardiogram; $\mathrm{FiO}_{2}$ : fraction of inspired oxygen; $\mathrm{MRl}$ : magnetic resonance imaging; $\mathrm{N}_{2} \mathrm{O}$ : nitrous oxide; $\mathrm{O}_{2}$ : oxygen; $\mathrm{PCO}_{2}$ : carbon dioxide partial pressure; $\mathrm{PetCO}_{2}$ : end-tidal carbon dioxide pressure; $\mathrm{PO}_{2}$ : oxygen partial pressure; $\mathrm{SpO}_{2}$ : pulse oxygen saturation

\section{Acknowledgements}

Not applicable.

\section{Funding}

This work was without financial support.
Availability of data and materials

All data and materials described in the manuscript will be freely available for non-commercial purposes.

\section{Authors' contributions}

WQF were responsible for obtaining the patient's informed consent, collecting the data of the patient, follow up, and preparation of the manuscript; $\mathrm{ZH}$ participated in the anesthesia and care of the patient and was responsible for revision of the manuscript. All authors read and approved the final manuscript

\section{Ethics approval and consent to participate}

Not applicable.

\section{Consent for publication}

Written informed consent was obtained from the patient for publication of this case report.

\section{Competing interests}

The authors declare that they have no competing interests.

\section{Publisher's Note}

Springer Nature remains neutral with regard to jurisdictional claims in published maps and institutional affiliations.

Received: 13 July 2018 Accepted: 3 December 2018

Published online: 22 December 2018

References

1. Hamilton BD, Gatti JM, Cartwright PC, Snow BW. Comparison of laparoscopic versus open nephrectomy in the pediatric population. J Urol. 2000;163(3):937-9

2. Mamić I, Danolić D, Puljiz M, et al. Pneumothorax and pneumomediastinum as a rare complication of laparoscopic surgery. Acta Clin Croat. 2016;55(3):501-4.

3. Waterman BJ, Robinson BC, Snow BW, et al. Pneumothorax in pediatric patients after urological laparoscopic surgery: experience with 4 patients. J Urol. 2004:171(3):1256-9.

4. Inderbir S, Kavoussi LR, Clayman RV, et al. Complications of laparoscopic nephrectomy in 185 patients: a multi-institutional review. J Urol. 1995: 154(2):479-83.

5. Del Pizzo JJ, Jacobs SC, Bishoff JT, Kavoussi LR, Jattett TW. Pleural injury during laparoscopic renal surgery: early recognition and management. J Urol. 2003;169:41-4.

6. PT Chui T. Gin and SCS Chung. Subcutaneous emphysema, pneumomediastinum and pneumothorax complicating laparoscopic vagotomy. Anaesthesia. 1993:48:978-81.

7. Heddle RM, Platt AJ. Tension pneumothorax during laparoscopic cholecystectomy. Br J Surg. 1992;79:374.

8. Kusaka J, Goto K, Yamamoto S. Pneumothorax during retroperitoneoscopic nephrectomy: a case report. Masui. 2004;53(12):1411-3.

9. Matsushita Y, Miyake H, Motoyama D. Contralateral pneumothorax during retroperitoneal laparoscopic donor nephrectomy: a case report. Asian J Endosc Surg. 2017;10(2):202-4.

10. Stern JA, Nadler RB. Pneumothorax masked by subcutaneous emphysema after laparoscopic nephrectomy. J Endourol. 2004;18(5):457.

11. Shanberg AM, Zagnoev M, Clougherty TP. Tension pneumothorax caused by the argon beam coagulator during laparoscopic partial nephrectomy. J Urol. 2002;168(5):2162.

12. Ozasa $\mathrm{H}$, Uchida H, Moto-Oka A. Intraoperative pneumothrax during retroperitoneal laparoscopic surgery. J Anesth. 2004;18(4):318-9.

13. Kadam PG, Marda M, Shah VR. Carbon dioxide absorption during laparoscopic donor nephrectomy: a comparison between retroperitoneal and transperitoneal approaches. Transplant Proc. 2008;40(4):1119-21.

14. Ng CS, Gill IS, Sung GT, Whalley DG, Graham R, Schweizer D. Retroperitoneoscopic surgery is not associated with increased carbon dioxide absorption. J Urol. 1999:162(4):1268-72.

15. Park HJ, Kim DK, Yang MK. Carbon dioxide pneumothorax occurring during laparoscopy-assisted gastrectomy due to a congenital diaphragmatic defect: a case report. Korean J Anesthesiol. 2016;69(1):88-92. 
16. Murdock CM, Wolff AJ, Van Geem T. Risk factors for hypercarbia, subcutaneous emphysema, pneumothorax, and pneumomediastinum during laparoscopy. Obstet Gynecol. 2000;95(5):704-9.

17. Ferzli GS, Kiel T, Hurwitz JB, Davidson P, Piperno B, Fiorillo MA, et al. Pneumothorax as a complication of laparoscopic inguinal hernia repair. Surg Endosc. 1997;11(2):152.

18. Aravind A, Shroff P, Dewoolkar L. Epigastric pain caused by pneumothorax following extubation in a case of transperitoneal laparoscopic nephrectomy. Intern J Anesthesiol. 2006;13(2). http://ispub.com/IJA/13/2/10355\#.

19. Hagopian EJ, Steichen FM, Lee KF, Earle DB. Gas extravasation complicating laparoscopic extraperitoneal inguinal hernia repair. Surg Endosc. 2001;15:324.

20. Potter SR, Kavoussi LR, Jackman SV. Management of diaphragmatic injury during laparoscopic nephrectomy. J Urol. 2001;165(4):1203-4.

21. Danielsen M, Højgaard L, Kjær A, Fischer BM. Positron emission tomography in the follow-up of cutaneous malignant melanoma patients: a systematic review. Am J Nucl Med Mol Imaging. 2014;4(1):17-28.

22. Schulze C, Hoppe H, Schweitzer W, Schwendener N, Grabherr S, Jackowski C. Rib fractures at postmortem computed tomography (PMCT) validated against the autopsy. Forensic Sci Int. 2013;233(1):90-8.

23. Lichtenstein DA, Mezière GA. Relevance of lung ultrasound in the diagnosis of acute respiratory failure*: the BLUE protocol. Chest. 2008;134(1):117-25.

24. Nagarsheth K, Kurek S. Ultrasound detection of pneumothorax compared with chest X-ray and computed tomography scan. Am Surg. 2011;77(4):480-4.

25. Volpicelli G, Boero E, Sverzellati N, Cardinale L, Busso M, Boccuzzi F. Semiquantification of pneumothorax volume by lung ultrasound. Intensive Care Med. 2014:40(10):1460-7.

26. Joris JL, Chiche JD, Lamy ML. Pneumothorax during laparoscopic fundoplication: diagnosis and treatment with positive end-expiratory pressure. Anesth Analg. 1995;81(5):993-1000.

27. Ludemann R, Krysztopik R, Jamieson GG, Watson DI. Pneumothorax during laparoscopy. Surg Endosc. 2003;17(12):1985-9.

28. Msezane LP, Zorn KC, Gofrit ON, et al. Case report: conservative management of a large capnothorax following laparoscopic renal surgery. J Endourol. 2007;21(12):1445-8.

29. Karayiannakis AJ, Anagnostoulis S, Michailidis K, Vogiatzaki T, Polychronidis A, Simopoulos C. Spontaneous resolution of massive right-sided pneumothorax occurring during laparoscopic cholecystectomy. Surg Endosc. 2005;15(2):100-3.

30. Togal T, Gulhas N, Cicek M, Teksan H, Ersoy O. Carbon dioxide pneumothorax during laparoscopic surgery. Surg Endosc. 2002;16:1242.

31. Mehran A, Brasesco O, De VE, Szomstein S, Rosenthal R. Intra-operative pneumothorax complicating laparoscopic roux-en-y gastric bypass. Obes Surg. 2004;14(1):124-8.

32. Altarac S, Janetschek G, Eder E, Bartsch G. Pneumothorax complicating laparoscopic ureterolysis. J Laparoendosc Surg. 1996;6(3):193-6.

33. Kumar G, Singh A. Pneumothorax during laparoscopic cholecystectomy. Med J Armed Forces India. 2007;63(3):277-8

34. Bala V, Kaur MD, Gupta N, Pawar M, Sood R. Pneumothorax during laparoscopic cholecystectomy: a rare but fatal complication. Saudi J Anaesth. 2011:5(2):238-9.

35. Phillips S, Falk GL. Surgical tension pneumothorax during laparoscopic repair of massive hiatus hernia: a different situation requiring different management. Anaesth Intensive Care. 2011;39(6):1120.

Ready to submit your research? Choose BMC and benefit from:

- fast, convenient online submission

- thorough peer review by experienced researchers in your field

- rapid publication on acceptance

- support for research data, including large and complex data types

- gold Open Access which fosters wider collaboration and increased citations

- maximum visibility for your research: over $100 \mathrm{M}$ website views per year

At BMC, research is always in progress.

Learn more biomedcentral.com/submissions 